\title{
UJI ANTI BAKTERI EKSTRAK ETANOL DAN ETIL ASETAT DAUN BINAHONG (Andredera cardifolia (Ten) Steenis) ASAL DESA SAKITA KABUPATEN MOROWALI TERHADAP Propionibakterium acnes
}

\author{
Sainal Edi Kamal ${ }^{1}$ Suprapto Prayitno ${ }^{2}$ \\ Jurusan Farmasi Politeknik Sandi Karsa ${ }^{1}$, Jurusan Farmasi Universitas Pancasakti ${ }^{2}$
}

\begin{abstract}
ABSTRAK
Berdasarkan catatan studi dermatologi kosmetika Indonesia didapatkan bahwa penderita ance vulgaris tahun 2006 sebanyak 60\% dan tahun 2007 sebanyak 80\%. Pada umunya insiden acne vulgaris terjadi sekitar usia $14-17$ tahun pada wanita dan 16 - 19 tahun pada pria. Penelitian ini bertujuan untuk mengetahui efek antibakteri ekstrak etanol dan etil asetat Daun Binahong dalam menghambat bakteri Propionibacterium acnes. Pengujian dilakukan dengan menggunakan metode difusi agar pada medium NA. Hasil penelitian didapatkan Pada konsentrasi ekstrak etanol $2 \%$ diameter rata-rata adalah $10 \mathrm{~mm}$, pada konsentrasi ekstrak etanol $4 \%$ diameter rata-rata adalah $12 \mathrm{~mm}$, pada konsentrasi ekstrak etanol $6 \%$ diameter rata-rata adalah $14 \mathrm{~mm}$, pada kontrol positif diameter rata-rata adalah 15,6 $\mathrm{mm}$. Sedangkan pada konsentrasi ektrak etil asetat $2 \%$ diameter rata-rata adalah $8,3 \mathrm{~mm}$, pada konsentrasi ektrak etil asetat $4 \%$ diameter rata-rata adalah $11 \mathrm{~mm}$, pada konsentrasi ektrak etil asetat $6 \%$ diameter rata-rata adalah $12,3 \mathrm{~mm}$ dan kontrol positif diameter rata-rata adalah $17 \mathrm{~mm}$. Zona hambat terbesar yang terbentuk pada konsetrasi ekstrak etanol adalah $6 \%$ dengan diameter rata-rata sebesar $14 \mathrm{~mm}$ dan zona hambat terbesar pada konsentrasi ekstrak etil asetat adalah $6 \%$ dengan diameter rata-rata sebesar 12,3 mm.
\end{abstract}

Kata Kunci: Daun Binahong, Ekstrak, Propionibacterium acnes

Coresponden Author:

Sainal Edi Kamal sainaledikamal@gmail.com 


\section{PENDAHULUAN}

\section{A. Latar Belakang}

Jerawat (acne vulgaris) merupakan suatu penyakit peradangan kronik dari unit pilosebaseus yang ditandai dengan adanya komedo, papula, pustula, nodul, kista dan skar (Saragih, dkk., 2016).

Jerawat dapat ditandai dengan timbulnya komedo, papul, pustul, nodul maupun skar. Tingkatan acne vulgaris dibagi menjadi acne ringan, sedang dan berat Acne vulgaris ringan ialah apabila jumlah komedo kurang dari 20, atau terdapat lesi inflamasi yang jumlahnya kurang dari 15 atau lesi total kurang dari 30 buah. Acne vulgaris sedang ialah apabila jumlah komedo 20100 atau terdapat lesi inflamasi $15-50$ buah dan Acne vulgaris berat ialah apabila terdapat lebih dari 100 komedo atau terdapat lebih dari 50 buah lesi inflamasi (Rosita SS, 2013).

Di Indonesia, catatan studi dermatologi kosmetika Indonesia didapatkan bahwa penderita ance vulgaris tahun 2006 sebanyak 60\% dan tahun 2007 sebanyak $80 \%$. Pada umunya insiden acne vulgaris terjadi sekitar usia $14-17$ tahun pada wanita dan 16 - 19 tahun pada pria (Kabau S, 2012). Baik dinegara maju maupun berkembang, penderita penyakit jerawat lebih tinggi pada wanita dibandingkan pria dengan puncak usia 15 tahun (Lynn, dkk., 2016). Penyebab terjadinya jerawat antara lain faktor genetik, endokrin, psikis, musim, stres, makanan, keaktifan kelenjar sebasea, infeksi bakteri, kosmetika, dan bahan kimia lain (AlHoqail, 2003). Jerawat dapat disebabkan oleh aktivitas kelenjar minyak yang berlebihan dan diperburuk oleh infeksi bakteri. Bakteri penyebab jerawat terdiri dari Propionibacterium acnes, Staphylococcus aureus, Staphylococcus epidermis (Noer Erin M dan Aliyah Nur H, 2018).

Antibiotik digunakan sebagai salah satu cara efektif dalam pengobatan jerawat, seperti klindamisisn, tetrasiklin, dan eritromisin (Guay, 2007). Tetapi, penggunaan antibiotik yang tidak tepat dapat menyebabkan resistensi (Sholih, dkk., 2015). Oleh karena itu, diperlukan adanya terapi alternatif dari tumbuhan yang berpotensi tinggi sebagai antibakteri. Indonesia dikenal sebagai salah satu Negara yang memiliki keanekaragaman hayati terbesar didunia dengan julukan Mega diversity, keanekaragaman hayati ini dapat dilihat dalam berbagai macam tumbuhan yang secara tradisional dapat digunakan untuk penyembuhan berbagai macam penyakit. Daun merupakan bagian yang kerap dimanfaatkan sebagai obat-obatan herbal salah satunya daun binahong (Mardiana, 2012)
Tanaman binahong (Andredera cardifolia (Ten.) Steenis). Telah dikenal memiliki khasiat penyembuhan yang luar biasa dan telah ribuan tahun dikonsumsi oleh bangsa Tiongkok, Korea dan Taiwan. Dalam penggunaanya bisa diminum, ditempel, dan dihirup. Tanaman binahong berasal dari Amerika Selatan, merupakan tanaman menjalar dan panjangnya bisa sekitar 5 meter, tanaman ini tumbuh baik dicuaca tropis, Di Indonesia binahong mempunyai nama yang berbeda diantaranya gendol, gendolak, kandula, uci-uci, duyumu, genjorat, garang-garang dan lembayung (Susetya, 2012).

Daun binahong mempunyai banyak khasiat dalam menyembuhkan berbagai macam penyakit ringan maupun berat. Kandungan di dalam daun binahong telah teruji klinis mengandung antioksidan, asam askorbat, fenol, dan protein yang cukup tinggi yang dapat mereduksi radikal bebas dalam tubuh (Fitri G, 2018).

Kondisi tersebut mendorong untuk dilakukanya pengembangan penelitian uji antibakteri ekstrak etanol dan etil asetat daun binahong terhadap bakteri Propionibacterium acnes.

\section{B. Rumusan Masalah}

1. apakah ekstrak etanol dan etil asetat daun binahong dapat menghambat bakteri Propionibacterium acnes?

2. seberapa besar nilai zona hambat yang terbentuk pada ekstrak etanol dan etil asetat terhadap Propionibacterium acnes?

\section{Tujuan Penelitian}

1. Untuk mengetahui ekstrak etanol dan etil asetat daun binahong dapat menghambat bakteri Propionibacterium acnes.

2. Untuk mengetahui nilai besar daya hambat yang terbentuk pada ekstrak etanol dan etil asetat daun binahong terhadap Propionibacterium acnes yang dilihat dari zona hambatanya.

\section{Manfaat Penelitian}

a. Memperkaya ilmu pengetahuan, khusunya yang bekaitan dengan adanya antibakteri suatu tanaman

b. Memberikan informasi bahwa ekstrak daun binahong Anredera Cardifolia (Ten.) Stennis dapat digunakan sebaai zat anti bakteri

c. Memberikan motivasi pada masyarakat untuk menggunkan zat anti bakteri dari bahan alam. 


\section{METODE PENELITIAN}

\section{A. Jenis Penelitian}

Penelitian ini merupakan studi eksperimental laboratorium yang menggunakan Prepionibacterium acnes sebagai bakteri percobaan.

\section{B. Lokasi dan Waktu Penelitian}

Penelitian ini telah dilakukan pada bulan September 2020 di Laboratorium Farmakognosi dan Fitokimia Politeknik Sandi Karsa Makassar dan Laboratorium Mikrobilogi Farmasi Universitas Pancasakti Makassar\

\section{Alat dan bahan}

Alat yang digunakan pada penelitian ini adalah bejana maserasi, batang pengaduk, tabung reaksi (pyrex), corong (iwaki), gelas ukur (pyrex), labu erlenmeyer (iwaki), termometer, cawan petri (iwaki), rotavapor (Buchi), water bath (LabTech), incubator (memmert), autoclave (GEA YX 280D), sendok tanduk, pipet tetes, kawat ose, paper disk, pinset, bunsen, gelas kimia (pyrex), neraca analitik (karl kolb), kain flannel, kertas pH.

Bahan yang digunakan dalam pada penelitian ini adalah aquadest, larutan $\mathrm{NaCL} 0,9 \%$, medium Natrium Agar (NA), Na-CMC, aqua pro injeksi, biakan murni bakteri Prepionibacterium acnes.

\section{Pengolahan Sampel}

\section{a. Pengambilan Bahan Uji}

Daun binahong (Anredera cordfolia (Ten.)Steenis) diperoleh dari Desa Sakita Kabupaten Morowali, Provinsi Sulawesi Tengah. Pengambilan sampel dilakukan pada pagi hari, pukul 08.00 - 10.00 wita. Daun yang digunakan adalah daun yang masih segar dan berwarna hijau sempurna.

b. Pengolahan bahan

Bahan uji yang di peroleh disortasi basah, setelah itu disortasi kering yang merupakan tahap akhir pembuatan simplisia. kemudian dipotong-potong kecil kemudian dianginanginkan atau jemur pada tempat yang tidak terpapar sinar matahari langsung.

c. Pembuatan Ekstrak Etanol dan Etil Asetat Daun Binahong (Anredera cordifolia (Ten.) Steenis)

Ditimbang daun binahong kering sebanyak 350 gram dengan menggunakan timbangan simplisia, direndam dalam bejana kemudian diberi larutan etanol $96 \%$ sampai terendam sempurna. Bejana maserasi tersebut ditutup rapat, dibiarkan selama 5 hari di tempat sejuk dan sekali-kali diaduk. Dilakukan penggantian pelarut 3 kali dengan pelarut yang sama dan jumlah volume pelarut sebanyak setengah kali jumlah volume pelarut pada penyarian pertama. Hasil yang diperoleh kemudian diuapkan dengan penguap vakum atau penguap tekanan rendah hingga diperoleh ekstrak kental. Dilakukan proses yang sama pada pembuatan ekstrak etil asetat.

d. Sterilisasi alat

Semua alat yang digunakan khususnya alat-alat yang terbuat dari kaca terlebih dahulu disterilkan di autoklaf, peralatan dicuci dengan detergen, kemudian dicuci dan dibungkus kertas. Disterilkan dengan oven pada suhu $180^{\circ}$ $-200^{\circ} \mathrm{C}$ selama $1-2 \mathrm{jam}$.

e. Pembuatan medium

Untuk membuat $100 \mathrm{ml}$ NA ditimbang 2,0 gram media NA, kemudian dimasukkan kedalam erlenmeyer, dilarutkan dengan aquadest hingga $100 \mathrm{ml}$, di cek $\mathrm{pH}$ nya sampai $7,0 \pm 0,2$. Setelah itu dipanaskan sampai mendidih dan larut sempurna disumbat kapas lalu disterilkan dalam autoklaf selama 15 menit pada suhu $121^{\circ} \mathrm{C}$ dengan tekanan 1-1,5 atm.

f. Penyiapan Mikroba

Propionibacterium acnes sebagai bakteri uji diambil satu ose, diinokulasikan dengan cara digoreskan pada medium NA miring dan diinkubasikan pada suhu $37^{\circ} \mathrm{C}$ selama 24 jam. Hasil biakan murni diambil 1 ose kemudian disuspensikan dengan $10 \mathrm{ml} \mathrm{NaCL} \mathrm{0,9 \%} \mathrm{hingga}$ diperoleh kekeruhan yang sama dengan standar kekeruhan larutan Mc Farland 0,5.

g. Pembuatan suspensi Na-CMC $1 \%$

Sebanyak 1 gram Na-CMC dimasukkan dalam lumpang yang berisi $30 \mathrm{ml}$ aquadest yang telah di panaskan, didiamkan selama 15 menit hingga diperoleh massa yang transparan, lalu digerus sampai homogen kemudian dimasukkan kedalam labu ukur $100 \mathrm{ml}$ ditambahkan aquadest hingga $100 \mathrm{ml}$ dikocok hingga homogen.

h. Pembuatan Lautan Zat Uji

Dibuat konsentrasi ekstrak etanol dan etil asetat daun Binahong dengan variasi konsentrasi $2 \% \mathrm{~b} / \mathrm{v}, 4 \% \mathrm{~b} / \mathrm{v}$, dan $6 \% \mathrm{~b} / \mathrm{v}$. Konsentrasi $2 \%$ b/v, ditimbang ekstrak kental daun Binahong 0,2 gram dan disuspensikan dengan $\mathrm{Na}-\mathrm{CMC} 1 \%$ sampai volume $10 \mathrm{ml}$. pada konsentrasi $4 \% \mathrm{~b} / \mathrm{v}$ dan $6 \% \mathrm{~b} / \mathrm{v}$, dengan ditimbang sebanyak 0,4 gram dan 0,6 gram 
kemudian disuspensikan dengan $\mathrm{Na}-\mathrm{CMC} 1 \%$ b/v sampai volumenya $10 \mathrm{ml}$.

i. Pengujian Daya Hambat Ekstrak Daun Binahong

Disiapkan medium NA steril, kemudian dituang secara aseptis kedalam 6 cawan petri steril sebanyak $15 \mathrm{ml}$ dan dibiarkan memadat. Setelah itu dioleskan suspensi bakteri uji di atas media NA tersebut. Paper disk direndam dalam bahan uji ekstrak etanol dan etil asetat daun binahong $2 \% \mathrm{~b} / \mathrm{v}, 4 \% \mathrm{~b} / \mathrm{v}$, dan $6 \% \mathrm{~b} / \mathrm{v}$, kontrol positif Clindamicin serta kontrol negatif NaCMC. Kemudian diinkubasikan pada suhu $37^{\circ} \mathrm{C}$ selama $1 \times 24$ jam.

j. Pengamatan dan Pengukuran Diameter Hambatan

Pengamatan dan pengumpulan data dilakukan dengan mengukur daerah diameter hambatan terhadap pertumbuhan bakteri uji setelah diinkubasi selama 1x24 jam

\section{HASIL DAN PEMBAHASAN}

\section{A. Hasil Penelitian}

Setelah dilakukan uji antibakteri ekstrak etanol dan etil asetat daun Binahong (Andreda cardifolia (Ten) Stenis) Asal Desa Sakita Kabupaten Morowali terhadap bakteri Propionibakterium Acnes, ekstrak dengan konsentrasi $2 \%$ b/v, 4\% b/v, 6\% b/v, mampu menghambat pertumbuhan Propionibakterium Acnes dengan masa inkubasi 1 x 24 jam. Hasil pengukuran rata-rata diameter zona hambatan dapat dilihat pada tabel di bawah ini.

Tabel I. Hasil Pengukuran Diameter Zona Daya Hambat Ekstrak Etanol dan Ekstrak Etil Asetat Daun Binahong (Andreda cardifolia (Ten) Stenis) terhadap bakteri Propionibakterium Acnes

\section{B. Pembahasan}

Penelitian ini dilakukan untuk mengetahui efek antibakteri ekstrak etanol dan ekstrak etil asetat Daun Binahong (Anredera cordifolia) Asal Desa Sakita Kabupaten Morowali terhadap Prepionibacterium acne.

Binahong (Anredera cordifolia (Ten.) Steenis) adalah sejenis tanaman merambat yang dapat menghasilkan suatu senyawa metabolit sekunder yang mempunyai peranan sebagai antimikroba, yaitu diantaranya adalah asam ascorbat dan flavanoid, total fenol. Karena adanya kandungan senyawa tersebut maka dari itu dalam kehidupan sehari-hari tanaman binahong dapat dimanfaatkan sebagai tanaman obat tradisional yang dapat menyembuhkan berbagai macam penyakit termasuk penyakit akibat infeksi bakteri, misalnya dapat digunakan sebagai obat luka bakar, borok, dan lupa akibat operasi serta jenis penyakit lainya.

Metode yang digunakan dalam proses ekstraksi ini adalah metode maserasi. Penggunaan metode maserasi didasarkan pada praktisnya pengerjaan dan alat yang digunakan sederhana dan mudah. Tetapi kelemahannya adalah waktu pengerjaannya yang membutuhkan waktu lama. Maserasi dilakukan dengan cara merendam serbuk simpilisia dalam cairan penyari. Pelarut yang digunakan adalah pelarut etanol $96 \%$ dan etil asetat. Kemudian disaring (filtrat) dengan kain flanel. Hasil filtrasi diuapkan dalam oven 510C sampai menjadi pekat (ekstrak).

Dalam penelitian ini pelarut yang digunakan adalah pelarut etanol dan etil asetat. Pemilihan jenis pelarut harus mempertimbangkan beberapa faktor antara lain selektivitas, kemampuan untuk mengekstrak, toksisitas, kemudahan untuk diuapkan dan hara pelarut (Harbone, 1987). Larutan pengekstraksi yang digunakan disesuaikan dengan kepolaran senyawa yang diinginkan. Menurut prnsip like dissolves like, suatu pelarut akan cenderung melarutkan senyawa yang mempunyai tingkat kepolaran yang sama (Suryani, 2015).

Hal ini dikarenakan kemampuan dan sifat pelarut dalam melarutan senyawa flavanoid berbeda beda, tergantung dari tingkat kepolaran pelarut dan senyawa yang diekstrak (Suryani 2015). Menurut prinsip polarisasi suatu senyawa akan larut pada pelarut yang mempunyai kepolaran yang sama (Harbone, 1987). Senyawa flavonoid terbagi menjadi beberapa jenis, tiap jenis flavonoid mempunyai kepolaran mempunyai kepolaran yang

\begin{tabular}{ccccccc}
\hline Bahan Uji & Replikasi & \multicolumn{5}{c}{ Diameter Zona Hambatan (mm) } \\
\cline { 2 - 7 } & & $\begin{array}{c}\text { Kontrol } \\
\mathbf{( - )}\end{array}$ & $\mathbf{2 \%} \mathbf{b} / \mathbf{v}$ & $\mathbf{4 \%} \mathbf{b} / \mathbf{v}$ & $\mathbf{6 \%} \mathbf{b} / \mathbf{v}$ & $\begin{array}{c}\text { Kontrol } \\
(+)\end{array}$ \\
\hline \multirow{2}{*}{$\begin{array}{c}\text { Ekstrak } \\
\text { etanol }\end{array}$} & I & 6 & 9 & 13 & 15 & 16 \\
\cline { 2 - 7 } & II & 6 & 10 & 11 & 14 & 15 \\
\cline { 2 - 7 } & III & 6 & 11 & 12 & 13 & 16 \\
\cline { 2 - 7 } & Total & 18 & 30 & 36 & 42 & 47 \\
\cline { 2 - 7 } Rata-rata & 6 & 10 & 12 & 14 & 15,6 \\
\hline Ekstrak & I & 6 & 8 & 10 & 14 & 17 \\
\cline { 2 - 7 } etil asetat & II & 6 & 9 & 11 & 11 & 16 \\
\cline { 2 - 7 } & III & 6 & 8 & 12 & 12 & 18 \\
\cline { 2 - 7 } & Total & 18 & 25 & 33 & 37 & 51 \\
\cline { 2 - 7 } & Rata-rata & 6 & 8,3 & 11 & 12,3 & 17 \\
\hline
\end{tabular}

berbeda-beda terangantung dari jumlah dan posisi gugus hidroksil tiap jenis flavonoid sehingga hal 
tersebut akan mempengaruhi kelarutan flavonoid pada pelarut.

Flavonoid merupakan senyawa golongan polifenol yang terditribusi luas pada tumbuhan dalam bentuk glikosida yang berikatan dengan suatu gula, karena itu flavonoid mrupakan senyawa yang bersifat polar. Pelarut polar yang biasa digunakan untuk ekstraksi flavanoid adalah metanol, aseton, butanol, etanol, air dan isopropanol (Suryani, 2015). Sedangkan aglikon flavonoid yang kurang polar misalnya isoflavon, flavanone, dan flavon serta flavanol cenderung lebih mudah larut dalam eter dan kloroform (Markham, 1998).

Etanol merupakan pelarut polar dimana etanol larut dalam air dan pelarut organik lainya sehingga dapat melarutan komponen yang mudah larut dalam air. Sifat-sifat fisika etanol utamanya dipengaruhi oleh keberadaan gugus hidroksil dan pendeknya rantai karbon etanol (Suarasa, 2011). Dan juga etanol dipertimbangkan sebagai penyari karena lebih selektif, kapang dan khamir sulit tumbuh dalam etanol $20 \%$ keatas, tidak beracun, netral dan absorbsinya baik.

Etil asetat pelarut semi polar dan dapat melarutkan senyawa semi polar pada dinding sel seperti aglikon flavonoid (Harbone, 1987). Etil asetat juga adalah pelarut polar menengah yang volatil, tidak beracun, dan tidak higroskopis. Etil asetat dapat menyaring senyawa-senyawa yang dapat memberikan aktivitas antibakteri diantaranya flavonoid pilohidroksi dan fenol yang lain (Khunaifi, 2010).

Proses maserasi dilakukan sebanyak 5 x 24 jam. Hal ini bertujuan untuk memaksimalkan proses pengambilan senyawa-senyawa kimia yang terdapat pada sampel daun Binahong. Selama proses perendaman, sampel disimpan dalam wadah tertutup dan terlindung dari cahaya langsung yang bertujuan untuk mencegah reaksi katalisis cahaya ataupun perubahan warna.

Pada penelitian yang dilakukan menggunakan 3 cawan petri pada setiap ekstrak etanol $96 \%$ dan etil asetat. dimana pada setiap konsentrasi, kontrol positif dan kontrol negatif dilakukan 3 replikasi. Dimana pada setiap cawan petri diletakkan masing-masing 5 paper disc dengan konsentrasi yang berbeda beserta kontrol positif dan negatif, dihasilkan zona hambatan yang berbeda pula. Dilihat dari adanya pertumbuhan mikroorganisme pada lingkaran transparan disekitar paper disc disebabkan oleh proses difusi ekstrak Daun Binahong (Anredera cordifolia
(Ten.) Steenis) yang menghambat mikroorganisme Propionibacterium acnes

Hasil pengukuran diameter zona hambat memperlihatkan peningkatan diameter zona hambat seiring dengan kenaikan konsentrasi ekstrak Daun Binahong. Data penelitian untuk ekstrak etanol diolah menggunakan program SPSS 25 one way anova. Analisis yang pertama yaitu dengan metode Shapiro Wilk untuk mengetahui normalitas data dan nilai P/Sig yang diperoleh yaitu 0 (K-), 1.000 (ekstrak 2\%), 1.000 (ekstrak 4\%), 1.000 (ekstrak 6\%) dan 0.000 (K-) yang artinya jika nilai $\mathrm{P} / \mathrm{Sig}>0,05$ maka data terdistribusi normal. Tetapi pada data $(\mathrm{K}+)$ menunjukkan data terdistribusi tidak normal $(\mathrm{P}<0,05)$. Kemudian dilakukan analisis uji homogenitas varian, nilai $\mathrm{P} / \mathrm{Sig}$ yang didapat yaitu 0.364 , karena nilai $\mathrm{P} / \mathrm{Sig}>0,05$ maka data homogen.

Pada ekstrak etil asetat data dan nilai $\mathrm{P} / \mathrm{sig}$ yang diperoleh yaitu 0 (K-), 0.000 (ekstrak $2 \%$ ), 1.000 (ekstrak 4\%), 0,637 (ekstrak 6\%) dan 1.000 $(\mathrm{K}+)$ yang artinya jika nilai $\mathrm{P} / \mathrm{Sig}>0,05$ maka data terdistribusi normal. Tetapi pada data (2\%) menunjukkan data terdistribusi tidak normal $(\mathrm{P}<0,05)$. Kemudian dilakukan analisis uji homogenitas varian, nilai $\mathrm{P} / \mathrm{Sig}$ yang didapat yaitu 0,161 karena nilai $\mathrm{P} / \mathrm{Sig}>0,05$ maka data homogen.

Dari analisis Anova nilai P/sig yang diperoleh ekstrak etanol dan etil asetat yang diperoleh 0,000 artinya terdapat perbedaan nyata antara kelompok perlakuan. Oleh karena dilakukan uji lanjutan (Post Hoc Test) yaitu LSD test.

Pada uji lanjutan ekstrak etanol $4 \%$ dengan 6\% tidak memperoleh hasil signifikan/tidak berbeda nyata, sedangkan pada ekstrak etil asetat memperoleh hasil yang signifikan.

\section{PENUTUP}

\section{A. Kesimpulan}

Berdasar hasil penelitian yang dilakukan, maka dapat disimpulkan bahwa:

1. Ekstrak etanol dan etil asetat daun binahong (Anredera cordifolia (Ten) Steenis) dapat menghambatpertumbuhanpropionibacterium acnes

2. Zona hambat terbesar yang terbentuk pada konsetrasi ekstrak etanol adalah 6\% dengan diameter rata-rata sebesar $14 \mathrm{~mm}$ dan zona hambat terbesar pada konsentrasi ekstrak etil asetat adalah 6\% dengan diameter rata-rata sebesar $12,3 \mathrm{~mm}$.

\section{B. Saran}


Disarankan dilakukan penelitian lebih lanjut untuk aktivitas antibakteri ekstrak Daun Binahong dengan menggunakan jenis bakteri lain.

\section{DAFTAR PUSTAKA}

Al-Hoqail, I. 2003. Knowledge, Beliefs and Perception of Youth Toward Acne Vulgaris. Saudi Med J. 24(7): 765-768

Anggita Rahmi H, Tri Cahyanto, Toni Sujarwo, Rahayu Indri Lestari. Uji aktivitas Antibakterii Estrak Daun Binahong (Pluchea indica L) Less) Terhadap Propionibacterium Acnes Penyebab Jerawat. Research gate, vol. 9 N0. 1, Juni 2015.

Agustina, N. 2013. Pengaruh Pemberian Ekstrak Daun Binahong (Andredera cordifolia (Ten) Steenis) Terhadap Kadar Kolesterol Total Mancit Putih Jantan. Padang: Sekolah Tinggi Ilmu Farmasi

Akiyama, H. F. K., Yamasaki, O., Oono, T., Dan Iwatsuki, K. 2001. Antibacterial Action Of Several Agains Staphylococcus aureus. Vol 48: $487-491$

Brooks, Geo F., Janets. Butel \& Stephen A. Morse. 2008. Mikrobiologi Kedokteran, alih bahasa Huriawati Hartono. Jakarta: Penerbit Buku Kedokteran EGC

Chusni TPT., Dan Lamb AJ. 2005. Antimicrobial Activity Of Flavonoids. International Jurnal Of Antimicrobial Agents: 26:343-356.

Ditjen POM. 2000. Parameter Standar Umum Ekstrak Tumbuhan Obat. Jakarta: Departement Kesehatan RI

Djide, M.N., Sartini. 2005. Instrumen Mikrobiologi Farmasi, Laboratorium Mikrobiologi Farmasi, F. MIPA, UNHAS. Makassar

Dzen, M.R. 2003. Bakteriologi Medik Edisi Pertama. Malang: Bayumedia Publishing

Erin N.M., Nur A.H. 2018. Aktivitas Antibakteri Ekstrak Kulit Buah Manggis (Garnica mangotana L.) Terhadap Bakteri Penyebab Jerawat. Bandung: Fakultas Farmasi Universitas Padjadjaran
Fitri, G. 2018. Tanaman Ajaib. Jakarta: Pustaka Makmur

Guay, D. R. P. 2007. Topical Clindamycin in The Management of Acne Vulagris. Expert Opin. Pharmacother. 8(15): 2625-2664

Harbone, J. B., 1987. Metode Fitokimia: Penuntun Cara Modern Menganalisis Tumbuhan oleh J. B. Harbone. Cetakan kedua. Diterjemahkan oleh Kosasih Padmawinata dan Iwang Soediro. Bandung: ITB

Kabau, S. 2012. Hubungan Antara Pemakaian Jenis Kosmetik Dengan Kejadian Acne Vulgaris. Jurnal Media Medika Muda

Khunaifi, M. 2010. Uji Aktivitas Antibakteri Ekstrak Daun Binahong (Andredera cardifolia (ten.) Steenis) Terhadap Bakteri Staphylococcus aureus dan Pseudomonas aeruginosa. Skripsi. Malang: UIN Malang.

Lynn, D. D., Tamara Umari, Caori A. D., dan Robert P. D. 2016. The Epidemiology of Acne Vulgaris In Late Adolescence. Adolescent Health, Medicine and Therapeutic

Mardiana, L. 2012. Daun Ajaib Tumpas Penyakit. Jakarta: Penebar Swadaya

Meutia T. A,. Umiana T. S. 2016. Manfaat Daun Binahong (Anredera cordifolia) Sebagai Terapi Acne Vulgaris. Lampung: Fakultas Kedokteran Universitas Lampung

Mellian, D. 2014. Pengaruh Ekstrak Daun Binahong (Andredera cordifolia (Tenore) Steen) Terhadap Kadar Asam Urat Pada Mancit Putih Jantan Hiperurisemia. Padang: Sekolah Tinggi Ilmu Farmasi

Maharti, I. D., 2007. Efek Antibakteri Ekstrak Daging Buah Avokad (Persia americana) Terhadap Steptococcus mutans. Respositori. Fakultas Kedokteran Gigi. Universitas Indonesia

Markham, K.R., 1998. Cara Mengidentifikasi Flavanoid. Terjemahan Kosasih Padmawinata. Bandung: ITB

Ngajow, M., Jemmy A., Dan Kamu VS. 2013. Pengaruh Antibakteri Ekstrak Kulit Batang Matoa (Pometia pinnata) Terhadap Bakteri 
Staphylococcus aureus Secara In Vitro. Manado: Universitas Sam Ratulangi

Price, A.S., Lorraine M. Wilson. 2006. Patofisiologi: Konsep Klinis Proses-Proses Penyakit, alih bahasa Peter Anugrah. Jakarta: EGC

Pelzhar, M dan Chan. 1986. Dasar - dasar Mikrobiologi 1. Jakarta: Universitas Indonesia. UI Press

Pelzhar, M dan Chan. 1998. Dasar - dasar Mikrobiologi (Jilid1). Jakarta: Universitas Indonesia

Rosita, S.S. 2013. Derajat Penyakit Acne Vulgaris Berhubungan Positif Dengan Kadar MDA. Denpasar: Fakultas Kedokteran Universitas Adayana

Rachmawati, S. 2007. Studi Mikroskopi Dan Skrining Fitokimia daun Andredera cardifolia (Ten) Steenis. Surabaya: Fakultas Farmasi UNAIR Surabaya

Robinson, T. 1991. Kandungan Organik Tumbuhan Tinkat Tinggi. Diterjemahkan Oleh Kosasih Padmawinata. Bandung: ITB

Saragih, D.F., Hendri Opod, dan Cicilia Pali. 2016. Hubungan Tingkat Kpercayaan Diri dan Jerawat Pada Siswa-Siswi Kelas XII di SMA Negri 1 Manado. Jurnal e-Biomedik (eBM). 4(1).

Susetya, D. 2010. Khasiat \& Manfaat Daun Binahong. Yogyakarta: Pustaka Baru Press

Suarsa, IW, Suarya, P \& Kurniawati, I., 2011. Optimasi Jenis Pelarut Dalam Ekstraksi Zat Warna Alam Dari Batang Pisang Kepok (Musa paradisiaca L) dan Batang Pisang Susu (Musa paradisiaca L). Jurnal Kimia Vol.5, no. 1, hal. 72-80.

Sholih, M.G., Ahmad M., dan Siti S. 2015. Rasionalitas Penggunaan Antibiotik di Salah Satu Rumah Sakit Umum di Bandung Tahun 2010. Jurnal Farmasi Klinik. 4(1): 63-70

Setiaji, A. 2009. Uji Aktivitas Antibakteri Ekstrak Petroleum eter, Etil asetat, Dan Etanol 70\% Rhizoma Binahong (Andredera cordifolia (Ten) Steenis) Terhadap Staphylococcus aureus ATCC 25923 dan Eschericia Coli ATCC 11229 Serta Skrining Fitokimianya. Surakarta: Fakultas Farmasi UMS Surakarta

Vasantkumari, R. 2007. Textbook of Microbiology. Mumbai: BI Publication Pvt Ltd

Yuliani, S.H., Fudholi, A., Pramono, S., \& Marchaban. 2012. The Effect of Formula to Physical Properties of Wound Healing Gel of Ethanolic Ekstract of Binahong (Andredera cordifolio (Ten) Steenis). International Journal of Pharmaceutical Sciences and Reseach. 3(11): 4254-42 